\title{
Idiopathic thrombocytopenia, initial illness and long term follow up
}

\author{
R W WALKER AND W WALKER \\ Departments of Haematology and Child Health, University of Newcastle upon Tyne
}

SUMmARY One hundred and eighty one children with thrombocytopenia for which no cause could be found have been studied. One patient died with severe bleeding possibly from disseminated intravascular coagulation and one developed cerebral haemorrhage, both within two weeks of onset. Ninety one per cent of the 135 with acute disease but only $36 \%$ of those with chronic disease remitted spontaneously. Twenty per cent of spontaneous remission occurred more than one year after onset. Six patients have run an intermittent course for 10 to 20 years. Four patients have had symptomless thrombocytopenia for between 10 and 30 years. Of 32 children treated by splenectomy 24 maintained normal platelet values thereafter. One boy died from pneumococcal septicaemia two years after splenectomy but he had not received prophylactic penicillin.

One hundred and fifty eight patients were followed up 3 to 37 years (mean 16.4 years) after onset. None who recovered spontaneously or after splenectomy had had further bleeding problems. No patient nor immediate relative had developed other autoimmune disease. We consider that a short course of corticosteroids immediately after diagnosis is justified in all cases even though we cannot produce proof that it influences the course of the disease. We do not accept any place for long term immunosuppressant treatment.

The occurrence of petechiae, bruising, and mucosal haemorrhage suggests thrombocytopenia and a platelet count will immediately establish or exclude this diagnosis. There are many causes of thrombocytopenia, particularly in adults, but in children acute leukaemia and aplastic anaemia are the most important and can be proved by marrow examination. Where these and other causes have been excluded the term idiopathic thrombocytopenia purpura is used. Preceding or concomitant infection is often blamed, particularly if of acute onset, but whatever the precipitating factor the mechanism is often the development of platelet autoantibody ${ }^{1}$ and when this has been shown the term autoimmune thrombocytopenia purpura is acceptable. Acute self limiting and chronic persistent varieties are described but whether these are individual variants of the same disease or two distinct conditions is not established because not all cases fit into these two categories. In most cases complete recovery is to be expected but the risk of dangerous haemorrhage exists and this is greatest in the early weeks of the disease, particularly in patients with acute onset and severe mucosal bleeding. ${ }^{23}$

\section{Patients and methods}

Between 1950 and 1980, 181 children (91 girls, 90 boys) with unexplained thrombocytopenia aged between 4 months and 15 years were under our care. Diagnosis was based on the blood count but in recent years marrow examination has usually been carried out at presentation.

Patients were arbitrarily classified as 'acute' or 'chronic' depending simply on whether the history of bleeding before presentation was less or more than two weeks. There was a significant predominance of acute disease under the age of 2 years $(P=0 \cdot 025)$.

Since 1962 most patients have received a five week course of corticosteroids immediately after diagnosis. Splenectomy has been considered but not necessarily carried out in patients with thrombocytopenia persisting for more than one year.

During 1981 and 1982 we attempted to see all patients for follow up study. At this interview we enquired about general health and particularly about bleeding, infections, and autoimmune disease in the patient and the immediate family. Blood was taken for: 
(1) Blood count, including platelets, using a Coulter S plus II counter. A blood film was also examined and differential white cell count performed.

(2) Platelet antibody in serum was measured by the method of Berg and Solheim, a radioimmune assay using $125 \mathrm{I}$ labelled protein $\mathrm{A} .{ }^{4}$ Autoimmune screen using standard fluorescent antibody and haemagglutination techniques was done for nuclear, parietal cell, thyroid, mitrochondrial, smooth muscle, and reticulin antibodies and rheumatoid factor.

(3) Serum immunoglobulin A, G, and $M$ values were determined by standard Technicon autoimmune precipitation technique.

\section{Clinical features}

Four of the 181 children were lost to follow up within a year of diagnosis while still thrombocytopenic, and are not considered further. In the remaining 177 patients the onset was 'acute' in $132(75 \%)$ and 'chronic' in $45(25 \%)$. The final results in these two categories of patient are summarised in Table 1.

Ninety per cent of patients with a short history but less than $40 \%$ of those with insidious onset recovered spontaneously ( $78 \%$ overall). For 123 of the 138 children who recovered spontaneously it was possible to time recovery accurately and this is summarised in Table 2. Of the 123 patients who remitted spontaneously 83 did so within three months including three with 'chronic' onset and it is possible that in these the long history of "easy bruising' did not really indicate prolonged thrombocytopenia. Twenty two remitted after one year; three remitted as long as five, 9, and 19 years respectively after onset.

The platelet value at follow up for patients who recovered spontaneously after 'acute' onset was mean (SD) $299(106) \times 19^{9} / 1$ and for the chronic cases was $254(122) \times 10^{9} / 1$. Six patients (two 'acute', four 'chronic') have run an intermittent usually symptomless course for 4 to 24 years with platelet values between 50 and $200 \times 10^{9} / 1$ and probably continue to have active but compensated disease.

Skin haemorrhage was the predominant clinical feature in both acute and chronic forms of the disease but severe mucosal haemorrhage was more common in acute disease. The pattern of haemorrhage was not directly related to outcome but the two patients with dangerous haemorrhage both presented acutely with severe mucosal bleeding.

The only patient who died was aged 7 years and was admitted in 1952 with a 13 day history of purpura. During the previous two days he had had severe epistaxis and vomiting of blood, and on admission late in the evening his haemoglobin was 9 $\mathrm{g} / \mathrm{dl}$, white blood count $15 \times 10^{9} / \mathrm{l}$ with $80 \%$ neutrophils, and his platelet count was less than $20 \times 10^{9} / 1$. During the night he was found moribund with a temperature of $104^{\circ} \mathrm{F}$ and died shortly afterwards. At necropsy no cerebral or adrenal haemorrhage was evident to the naked eye but histological details are not available. Although his gut contained a large quantity of blood and death was attributed to exsanguination, in retrospect he could have had a septicaemic illness with consumptive thrombocytopenia.

The patient who developed cerebral haemorrhage also presented in 1952 at the age of 8 years with a

Table 1 Duration of symptoms before presentation in relation to outcome

\begin{tabular}{|c|c|c|c|c|c|c|}
\hline & \multirow{2}{*}{$\begin{array}{l}\text { Result } \\
\text { known }\end{array}$} & \multirow{2}{*}{$\begin{array}{l}\text { Spontaneoust } \\
\text { cure }\end{array}$} & \multicolumn{2}{|c|}{ Splenectomy } & \multirow{2}{*}{$\begin{array}{l}\text { Persistent }^{*} \\
\text { thrombocytopenia }\end{array}$} & \multirow{2}{*}{$\begin{array}{l}\text { Died } \\
\text { (haemorrhage) }\end{array}$} \\
\hline & & & Cured & Not cured & & \\
\hline Acute $\leqslant 2$ weeks & 132 & $122(92 \%)$ & 7 & 0 & 2 & 1 \\
\hline Chronic $>2$ weeks & 45 & $16(36 \%)$ & 17 & 8 & 4 & 0 \\
\hline All cases & 177 & & & & & \\
\hline
\end{tabular}

*Symptomless thrombocytopenia many years after diagnosis.

+Forty seven 'acute' and 21 'chronic' cases had received a short course of prednisone immediately after diagnosis.

Table 2 Duration of observed thrombocytopenia before 'spontaneous' remission

\begin{tabular}{lllllllll}
\hline Onset & $\begin{array}{l}\text { Number } \\
\text { assessible }\end{array}$ & 3 mths & $3-6$ mths & $6-12$ mths & $1-2$ yrs & $2-3$ yrs & $3-4$ yrs & $>4$ yrs \\
\hline Acute' & 107 & 80 & 13 & 5 & 2 & 2 & - \\
'Chronic' & 16 & 3 & - & - & 3 & 3 & - & 6 \\
\hline
\end{tabular}

Twenty two $(18 \%)$ out of 123 remitted after 1 year. 
two week history of bruising and petechiae and had developed epistaxis, melaena, and haematuria two days before admission. Oral purpura and conjunctival haemorrhage were prominent features. She was treated immediately with prednisone but two days later developed generalised convulsions lasting 15 seconds followed by unconsciousness lasting several hours. She had papilloedema and retinal haemorrhage particularly on the right side. Cerebrospinal fluid was straw coloured with slight increase in protein but no cells; her electroencephalogram was normal; and neck and back stiffness persisted for several days. She survives $\mathbf{3 0}$ years later with a normal platelet count but a possible behaviour defect, having had a number of convictions for theft.

There was no clear cut seasonal distribution and 'chronic' cases in particular occurred equally throughout the year. Direct questioning showed preceding infection in only 55 patients: 12 rubella; 7 measles; 22 presumed upper respiratory infection; and occasional instances of chicken pox, whooping cough, and scarlet fever. Some patients had received penicillin or other antibiotics in the weeks preceding onset but most children gave no history of infection or drug intake.

\section{Marrow examination}

Marrow examination was carried out in 41 patients at the time of diagnosis. Aspirated material from the iliac crest was used for direct films and the residual fragments were cut for sections. The estimated number of megakaryocytes was based on sectioned material and was considered normal in 14 patients but increased in 27 , and few if any megakaryocytes showed active platelet production. Four patients had an apparent increase of eosinophils in the marrow. Neither of these features was related to outcome.

\section{Treatment by corticosteroids}

Forty seven 'acute' patients had been treated with prednisone and the results were compared with 63 historic controls matched for age, sex, and type of onset. The end result was similar for both groups; $85 \%$ of the prednisone treated patients recovered spontaneously compared with $92 \%$ of those not treated in this way. Moreover, the ultimate time of recovery was the same for both groups. Twenty one 'chronic' patients were treated with similar courses of prednisone. Five had a temporary rise in platelets but in none was this sustained.

\section{Treatment by splenectomy}

Splenectomy was considered whenever thrombocytopenia persisted for at least one year. When the
Table 3 Effect of corticosteroids in acute idiopathic thrombocytopenia

\begin{tabular}{lllll}
\hline Platelet response & \multicolumn{2}{l}{ Final result } & & \\
\cline { 2 - 5 } & $\begin{array}{l}\text { Spontaneous } \\
\text { cure }\end{array}$ & $\begin{array}{l}\text { Persistent } \\
\text { thrombocytopenia }\end{array}$ & $\begin{array}{l}\text { Splenectomy } \\
\text { cure }\end{array}$ & $\begin{array}{l}\text { No } \\
\text { cases }\end{array}$ \\
\hline $\begin{array}{l}\text { Prednisone } \\
\text { Prompt } \\
\text { Delayed but } \\
\text { sustained }\end{array}$ & 22 & 0 & 0 & 22 \\
$\begin{array}{c}\text { Immediate but } \\
\text { temporary }\end{array}$ & 11 & 0 & 0 & 11 \\
$\begin{array}{c}\text { No response } \\
\text { Total }\end{array}$ & 4 & 1 & 2 & 6 \\
\hline $\begin{array}{c}\text { No prednisone } \\
\text { Prompt and } \\
\text { sustained }\end{array}$ & $40(85 \%)$ & 1 & 3 & 8 \\
$\begin{array}{c}\text { Delayed but } \\
\text { sustained }\end{array}$ & 19 & & & 47 \\
$\begin{array}{l}\text { Immediate but } \\
\text { temporary }\end{array}$ & 2 & 0 & 0 & 32 \\
$\begin{array}{c}\text { No response } \\
\text { Total }\end{array}$ & 5 & 0 & 0 & 20 \\
\hline
\end{tabular}

danger of septicaemia became known, however, this was carried out only if there was related disability. Thirty two patients were treated by splenectomy. Seven with 'acute' onset have all maintained normal platelet values since. Twenty five with 'chronic' onset had an immediate response but normal platelet values have been maintained in only 17 . In two, recurrence was associated with hypertrophy of ectopic splenic tissue.

In the Figure we have plotted platelet response in the year after splenectomy for 16 patients who achieved permanent response and 7 patients in whom response was only temporary. There was no difference between the two groups in the first two days after operation but in the following two weeks

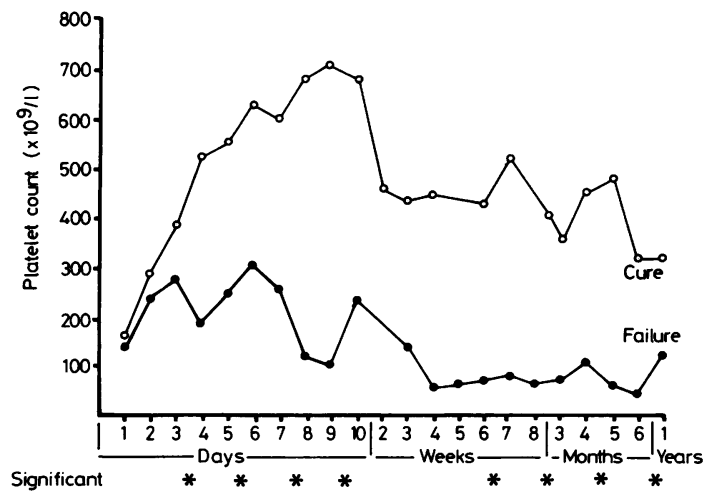

Figure Platelet values afer splenectomy in relation to outcome. 
those who were to derive permanent benefit sustained higher values than those who relapsed.

Patients achieving counts of over $500 \times 10^{9} / 1$ usually did well; those with peak values less than $300 \times 10^{9} / \mathrm{l}$ did not, although individual exceptions occurred. If at the end of the first postoperative week, however, the platelet count is not maintained at well over $200 \times 10^{9} / \mathrm{l}$, an unfavourable response is to be expected.

Prior response or otherwise to corticosteroids did not indicate response to splenectomy. Five 'acute' patients, who derived little benefit from corticosteroids all responded to splenectomy as did fifteen of 21 with 'chronic' illness.

Splenectomy is not without risk; the most important, particularly in children, being of overwhelming pneumococcal septicaemia usually within 2 to 3 years of operation. One patient in this series died from this complication and has been reported previously.

\section{Long term follow up study}

Four of the 181 patients are known to have died; one from exsanguination or disseminated intravascular coagulation shortly after onset, one from pneumococcal septicaemia within two years of splenectomy, one drowned 12 years after spontaneous recovery, and the fourth, known to have been thrombocytopenic 7 years after diagnosis, was killed in a car accident several years later. Of the remainder 158 $(89 \%)$ have been seen and hadblood countsperformed in the past two years, 142 by us and 16 by colleagues elsewhere in Britain, Canada, or Australia. Immunoglobulin values, fluorescent antibody screen, and serum platelet antibody assays were carried out in 141 of these patients.

The interval between diagnosis and follow up was from three to 35 years and in more than half was greater than 15 years. This was unrelated to clinical type, management, or end result.

All 158 patients were normal as judged by height, weight, school performance, and ultimate employment. Their haemoglobin value was mean (SD) $13 \cdot 7$ (2.0) $\mathrm{g} / \mathrm{dl}$; white cell count was mean (SD) $7 \cdot 7$ $(3 \cdot 2) \times 10^{9} / \mathrm{l}$, and mean platelet value was more than $250 \times 10^{9} / 1$.

No patient who remitted spontaneously or responded satisfactorily to splenectomy had further bleeding nor did any member of their immediate family. No patient had developed overt autoimmune disease nor had any member of their immediate family. Eight patients gave a history of atopic illness, asthma, eczema or hayfever.

Immunoglobulin (IgG, IgM, IgA) assays on 141 patients are given in Table 4. There was no significant difference between the major groups nor
Table 4 Immunoglobulin values (mean $S D)$ ) at follow up in relation to 'acute' and 'chronic' disease

\begin{tabular}{llll}
\hline & $\begin{array}{l}\lg G \\
(g / l)\end{array}$ & $\begin{array}{l}\lg A \\
(g / l)\end{array}$ & $\begin{array}{l}\operatorname{Ig} M \\
(g / l)\end{array}$ \\
\hline 108 'acute' cases & $10 \cdot 69(2 \cdot 36)$ & $2 \cdot(1)(0 \cdot 89)$ & $1.36(0 \cdot 74)$ \\
33 'chronic' cases & $12.22(2 \cdot 64)$ & $2 \cdot 39(0.92)$ & $1.46(0 \cdot 79)$ \\
Normal values & $11.20(3 \cdot 19)$ & $2 \cdot 19(1 \cdot 63)$ & $0 \cdot 89(0 \cdot 38)$ \\
\hline
\end{tabular}

in subgroups based on treatment and results; in particular low IgM values after splenectomy were not observed.

Immunofluorescent antibody screen in the same 141 patients showed antibody in 7, all of whom had recovered spontaneously. Four girls had thyroid antibody but are presently euthyroid. Three patients aged 10,12 , and 18 years had strong parietal cell antibodies but all have normal haemoglobin and plasma B12 values and in none was intrinsic factor antibody detected. The frequency of thyroid antibodies is no more than would be expected in a random local population of similar age but the presence of strong parietal cell antibodies in young people is unexpected.

Four patients (two 'acute', two 'chronic') have continuous, severe but asymptomatic thrombocytopenia $12,24,12$, and 27 years respectively after diagnosis. Two have undergone major surgical procedures without steroid or platelet cover and without undue bleeding. Six patients already referred to ran an 'intermittent' course with platelet values between 50 and $200 \times 10^{9} / 1$ but minimal disability. Seven 'chronic' patients had persistent thrombocytopenia despite splenectomy.

After spontaneous recovery, 27 women have had children. None have had any problem with undue bleeding at the time of delivery and no infant has been thought to have neonatal thrombocytopenia. Four patients successfully treated by splenectomy had infants without problem but two, one who was 'cured' and one who had recurrence, had infants with neonatal thrombocytopenia, all of whom were treated with steroids and survived. Bleeding at the time of delivery was not a problem, although only one of the three deliveries was covered with prophylactic platelet transfusion. Platelet antibody in serum was detected during the one pregnancy where tests were carried out but did not reach a significant value.

Platelet antibody was detected in the serum of 10 of 38 'chronic' and in 17 of 105 'acute' patients tested at follow up. The presence of antibody was not related to the clinical type, treatment, or end result, for example it was sometimes found in patients who had remitted spontaneously or not detected in the serum of patients with persistent thrombocytopenia. 


\section{Discussion}

Thrombocytopenia in children is usually idiopathic or has an easily diagnosed cause. Marrow examination is often useful in differential diagnosis but not in prognosis.

There is no accepted incidence of idiopathic thrombocytopenia in chidren. Lilleyman ${ }^{6}$ puts it at less than 10/100 000 children each year, but (if possible) this is an overestimate. A recent survey among paediatricians and haematologists in the Newcastle region suggests that idiopathic thrombocytopenia is no more common than acute leukaemia, that is $4 / 100000$ children each year.

Most authors recognise acute self limiting and chronic persistent forms of the disease but distinguishing criteria are not defined. Retrospective diagnosis is not helpful in planning early management and classification based on antibody or other tests has not proved reliable. ${ }^{47}$ For the present series we used one simple criterion. Based on a history of bruising of less or more than two weeks $75 \%$ of patients were classified as 'acute' and $25 \%$ as 'chronic', possibly an exaggeration of chronic disease due to special referral. ${ }^{x}$ Six patients after an initial period of active bleeding have thereafter maintained platelet counts in the range 10 to $200 \times 10^{9} / \mathrm{l}$ for many years with minimal symptoms. Do the 'acute', 'chronic', and 'intermittent' types" of this disease have the same pathogenesis?

Harrington et al ${ }^{1}$ showed that plasma from affected patients, when infused into normal volunteers could produce thrombocytopenia. The transferable factor was found to be in the IgG fraction. ${ }^{10}$ Increased quantities of platelet associated IgG have been found on platelets of patients with idiopathic thrombocytopenia. ${ }^{11}$ The IgG on the platelets seems to be monomeric and antigen specific. ${ }^{12} 13$ These raised $\mathrm{IgG}$ concentrations have also been found in other conditions. ${ }^{14}$ The presence of immune complexes in sera of affected patients has been reported. ${ }^{15}$ Localisation and quantitation of the site and degree of platelet destruction has been shown by the use of ${ }^{5}$ chromium and ${ }^{111}$ indium. ${ }^{16}$

This evidence supports the concept of an autoimmune disorder. The relative importance of the findings remains to be established. At this time, however, there is no evidence that any of the investigations provide results predicative of response to treatment. McMillan ${ }^{17}{ }^{18}$ has reviewed the subject but considers it still premature to assume that idiopathic thrombocytopenia always has an immune basis.

The use of corticosteroids in idiopathic thrombocytopenia is still controversial. ${ }^{689}{ }^{19}$ If 80 to $90 \%$ of affected children will remit rapidly and spon- taneously perhaps steroids should be reserved for those who fail to recover quickly. The major danger exists, however, in the early weeks of the disease and therefore corticosteroids should probably be given immediately, especially when onset has been 'acute' and mucosal haemorrhage a prominent feature. In addition, it is easy to justify a trial of corticosteroids when thrombocytopenia is persistent. It is our policy, therefore, to give a five week course to all patients at presentation even though we have been unable to prove a difference in long term result and speed of recovery. If used in this way side effects of corticosteroids are negligible and diminution in active bleeding is 'apparent' even when there is no change in the platelet count. Corticosteroids improve platelet economy ${ }^{20}$ and possibly have a direct effect on capillary fragility. Long term corticosteroids have serious side effects, may potentiate thrombocytopenia, ${ }^{21}$ and are not recommended. One child, not in the present series, came under our care after more than two years of maintenance treatment with prednisone. When this was stopped the condition improved dramatically and three years later the platelet count is still normal.

Other immune suppressants are often tried in chronic disease but their value is usually short lived and side effects not acceptable. ${ }^{69} 2223$ Any role for intravenous gammaglobulin has yet to be established, ${ }^{24} 25$ while plasmapheresis may find a place in the preparation of patients for surgery in acute emergencies. ${ }^{26}$

Four patients who presented with severe bleeding have almost certainly remained thrombocytopenic for as long as 20 years with minimal, if any, symptoms and even now spontaneous remission is a possibility.

What then is the role of splenectomy; either to remove the site of platelet sequestration or the primary site of antibody production? ${ }^{27}$ There may be a place for emergency splenectomy in life threatening cases ${ }^{2}$ but most workers would consider this only when thrombocytopenia has persisted for more than one year. ${ }^{60}$ Danger of fulminating pneumococcal septicaemia after splenectomy is greatest in infancy or under the age of five years and maximal in the first two to three years after operation. ${ }^{28}$ One child in this series died at the age of 10 years within two years of operation which was performed for prolonged, but symptomless thrombocytopenia. The danger can be reduced by preoperative immunisation against pneumococci and prophylactic penicillin for at least three years after operation but splenectomy for thrombocytopenia should probably be recommended only if there is disability. Previous response to steroids or otherwise does not indicate the likely response to splenectomy and the value of 
studies of antibody type and platelet survival in deciding this have not been evaluated. ${ }^{29}$ The platelet response in the first two weeks after operation, however, allows a good estimate of the long term result and if values of greater than $300 \times 10^{9} / 1$ are not sustained for this period a poor response is to be expected, although exceptions occur. In this series 32 patients underwent splenectomy; 24 derived long term benefit with normal platelet counts but 8 remain thrombocytopenic. Antibody may persist after splenectomy even in patients with normal platelet counts as in one patient in the present series whose infant suffered from neonatal purpura.

As idiopathic thrombocytopenia in children is rare, it is relevant to consider whether there might be some underlying defect in immune regulation, ${ }^{30-32}$ for thrombocytopenia can be a feature of disorders such as Aldrich's syndrome in children and systemic lupus erythematosus in adults.

We have direct knowledge of 158 patients in the past two years and information on 13 others for at least 10 years after diagnosis. All who remitted spontaneously or responded optimally to splenectomy have had no further bleeding problems. None of their immediate family have had any relevant bleeding disorder. None have developed other overt autoimmune or lymphoproliferative disease, nor have any of their immediate family. Immunoglobulin values were not different from a normal population of similar age and this was true when clinical subtypes of idiopathic thrombocytopenia were considered individually. Thyroid autoantibodies were detected in four girls but this is not more than would be expected in a random, local population. Three patients under the age of 20 years developed strong parietal cell antibodies but no other abnormality was shown and the importance, or otherwise, of this is not yet known. Surprisingly we found free serum platelet antibody in patients who had recovered both from acute and chronic forms of idiopathic thrombocytopenia and Ozsoylu et $a l^{33}$ found reduced platelet survival in similar patients.

\section{References}

1 Harrington WJ, Minnich V, Hollingsworth JW, Moore CV. Demonstration of thrombocytopenic factor in the blood of patients with thrombocytopenic purpura. $J$ Lab Clin Med 1951:38:1-10.

2 Zerella JT, Martin LW, Lampkin BC. Emergency splenectomy for idiopathic thrombocytopenia purpura in children. $J$ Pediatr Surg 1978;13:243-6.

${ }^{3}$ Komrower GM, Watson GH. Prognosis of ITP in childhood. Arch Dis Child 1954;29:502-6.

4 Berg OJ, Solheim BG. Detection of thrombocyte antibody by 125 I labelled protein A. Tissue Antigens 1978;12:189-94.
5 Walker JH, Walker W. ITP in childhood. Arch Dis Child 1961;36:649-57.

6 Lilleyman JS. Management of childhood idiopathic thrombocytopenia purpura. Br J Haematol 1983;54:11-4.

7 Tomar RH, Stuart TMJ. Predicting acute versus chronic childhood idiopathic thrombocytopenic purpura. Amer $J$ Dis Child 1981;135:446-9.

8 Zuelzer WW, Lusher JM. Childhood ITP. Am J Dis Child 1977;131:360-3.

9 Lusher JM, Iyer R. ITP in children. Semin Thromb Hemostas 1977:3:175-99.

10 Schulman NR, Marder VJ, Weinrach RS. Similarities between known antiplatelet antibodies and the factor responsible for thrombocytopenia in idiopathic purpura: physiologic, serologic and isothopic studies. Ann NY Acad Sci 1965;124:499-542.

11 Dixon R, Rosse W, Ebbert L. Quantitative determination of antibody in idopathic thrombocytopenia: correlation of serum and platelet bound antibody with clinical response. $N$ Engl J Med 1975;292:230-6.

12 Hymes K, Schulman S, Karpatkin S. A solid phase radioimmunoassay for bound antiplatelet antibody; studies on 45 patients with autoimmune platelet disorders. $J$ Lab Clin Med 1979;94:639-48.

13 McMillan R, Tani P, Mason D. The demonstration of antibody binding to platelet-associated antigens in patients with immune thrombocytopenic purpura. Blood 1980;56:993-5.

14 Kelton JG, Powers PJ, Carter CJ. A prospective study of the usefulness of the measurement of platelet associated IgG for the diagnosis of idiopathic thrombocytopenia purpura. Blood 1982;60:1050-3.

15 Trent RJ, Clancy RL, Danis V, Basten A. Immune complexes in thrombocytopenic patients: cause or effect? $\mathrm{Br} J$ Haematol 1980;144:645-54.

16 Heyns A Dup, Lotter MG, Badenhorst PN, et al. Kinetics and sites of destruction of 111 indium-oxine labelled platelets in idiopathic thrombocytopenic purpura: a quantitative study. $A m$ J Hematol 1982;12:167-78.

17 McMillan R. Childhood idiopathic thrombocytopenia purpura $N$ Engl J Med 1981;304:1135-47.

18 McMillan R. Immune thrombocytopenia. Clinics in Haematology 1983;12:69-78.

19 McElfresh AE. ITP to treat or not to treat. $J$ Pediatr 1975;87:160-1.

20 Branchog I, Weinfeld A. Platelet survival and platelet production in ITP before and during treatment with corticosteroids Scand J Haematol 1974:12:69-79.

21 Cohen P, Gardner FH. Thrombocytopenic effect of sustained high dose prednisone in ITP. $N$ Engl J Med 1961;265:611-7.

22 Ahn YS, Byrnes JJ, Harrington WH. The treatment of idiopathic thrombocytopenia with vinblastine-loaded platelets. N Engl J Med 1978;298:1101-7.

23 Ahn YS, Harrington WJ, Simon SR, Mylvaganam R, Pall LM, So AG. Danazol for the treatment of idiopathic thrombocytopenic purpura. N Engl J Med 1983:308:1396-9.

24 Imbach P. Hirst A, Rossi E, et al. High dose intravenous gammaglobulin for ITP in childhood. Lancet 1981;i:1228-30.

25 Mori PJ, Mancuso G, Del Principe D, et al. Chronic ITP treated with immunoglobulin. Arch Dis Child 1983;58:851-5.

26 Novak R. Williams J. Plasmapheresis in catastrophic complications of ITP. J Pediatr 1978;92:434-6.

27 Karpatkin M, Karpatkin S. Immune thrombocytopenia in children. Am J Pediatr Hematol Oncol 1981:3:213-9.

28 Walker W. Splenectomy in childhood: a review in England and Wales 1960-64. Br J Surg 1976;63:36-43.

29 Kernoff IM. Malan E. Platelet antibody levels do not correlate with response to therapy in ITP. Br J Haematol 1983;53: 559-62.

30) McIntosh S, Johnson C, Harigan P, Baumgarten A, Dwyer JM 
Immunoregulatory abnormalities in children with thrombocytopenia purpura. J Pediatr 1981;99:525-30.

${ }^{31}$ Clancy RL, Muller HK, Ward HA. Immune deficiency and grouping with thyrogastric autoimmune disease in patients with chronic idiopathic thrombocytopenic purpura. Aust NZ J Med 1974:4:243-6.

${ }^{32}$ Karpatkin S, Fotino M, Gibofski A, Winchester RJ. Association of HLA DRw2 with thrombocytopenic purpura. J Clin Invest 1979;63:1085-8.
33 Özsoylu S, Allahaedi H, Yahya L, Pirnar A. Platelet survival in childhood ITP in remission. $J$ Pediatr 1976;89;388-90.

Correspondence to Professor W Walker, Department of Haematology, The Royal Victoria Infirmary, Queen Victoria Road. Newcastle upon Tyne NE1 4LP.

Received 28 December 1983

\section{British Paediatric Association}

Annual meetings

1984 10-14 April York University

1985 16-20 April York University

1986 15-19 April York University

1987 7-11 April York University 